registers by diagnosis (the DHSS ought to know that, since they do not require it to be done), so of course we could not answer. 'Well. I'll tell them my age', said the secretary, and vanished. Some time later there duly appeared in Hansard, copied in The Times, Lancet, etc; 'In answer to a parliamentary question on 13 March, the Secretary of State said that xxxx alcoholics had been treated in NHS hospitals last year'-we knew that was a piece of rubbish over which many people had wasted time and money. If I were a different sort of chap I would have started a campaign to replace phoney figures with genuine data, and to press administrators to use them in taking rational decisions instead of preferring, as they do, to talk things over in ignorance and then decide by the light of nature. I think the NHS would at once become more efficient.

But who do you approach in such a campaign? Twenty-four years as a consultant in the NHS showed me over and over again that it is often very difficult to find out who (if anyone) is in charge, who is actually responsible for this or that category of decision in the NHS and which way the chain of responsibility runs. If you can identify the responsible person, you can write to them or speak with them. In the NHS it is more like writing to Santa Claus.

A ship has a captain, an orchestra has a conductor, a school has a headmaster, an army has officers and generals ... What is so unique about hospitals that they alone should function, with all their many different activities and many members of different professions together, without a head, an organizer, a responsible individual? Who will keep harmony, who will steer a course to avoid rocks and sandbanks, who will maintain order? No wonder there is waste, sinking morale, sad mishandling of patients, dirty worn-out wards and equipment. Without efficient management, the NHS is slowly choking itself to death.

The analysis I made of nursing and patient numbers used data already available, but it was no one's business to bring them together and analyse them. The hospital was running badly, and we individually could see some of the signs of this, but it was no one's business to see the full overall picture. The cure involved splitting off geriatric services and setting limits to their work; and also a complete reorganization of nursing services, which was very painful. Had there been an overall manager, it is unlikely that things would have gone wrong like this in the first place, or taken so long to correct. It was painful for the staff, and inhumane, even lethal, for some of the patients. We did not need an old-style superintendent, but we did need one person as responsible head.

Consultants think of research as something technical, involving apparatus, statistical calculation, grants, and leading to papers or degrees. But it is something much simpler: asking questions. Now that I look back I think that analysing the nurse distribution and the hospital's work was quite as much research as giving radioactive imipramine to rats, and of much more immediate use.

\section{Looking back}

'You will always do research', said Aubrey Lewis, and, on and off, this proved to be true. But looking back at all my quarter-finished projects, unpublished data, papers needing revision and shoved in a drawer, I see I was too much a loner, too fluctuating, too little the scholar, so in the end, apart from a few crumbs, I produced nothing. I needed someone to control my tendency to wander off on new projects, to carry me over periods of boredom or despondency, to encourage perseverance and contact with others. Nurturing potential research workers is a difficult art, akin to psychotherapy, but I fear that very few of us seniors see it like that. We raise difficulties all the time over the quality of projects, standards of the applicant's hospital, the need for money, and only help when the young man or woman shows great persistence. We do not often do positive things-repeated encouragement or spontaneous advice, helping the young worker to link up with more experienced groups and get specialized collaboration, and enquiring into the personal difficulties holding things up. Research is often seen as a luxury, or privilege, or some kind of hobby. Some of it, however, has a direct impact on everyday life. The atmosphere of enquiry improves the standard of clinical practice of everyone around, not just the researcher; the results of enquiry sometimes have an immediate effect on the organization of the week's clinical work. More generally, research brings commercial and international benefits to the whole community, as well as new health prospects. I enjoyed my life, I have no complaints, but I think society might have got more out of me if someone had turned me from an amateur into a professional.

\title{
Interdisciplinary Working Party Discussion Document; A Guide to Confidentiality in Relation to Mental Health
}

This discussion document, which has been approved by Council as a discussion document, was produced by a Working Party representing a range of disciplines and interests to try to produce a common understanding of the issue of confidentiality between clients and professionals, with the emphasis on the health and social services, and in particular, mental health services.

The discussion document attempts to examine the topic of confidentiality in relation to the various settings in which it has to operate and to state the principles and codes of practice that apply. Council agreed at its meeting in June that it provided a useful contribution to the continuing debate on confidentiality. Whilst it could not be seen as a document reflecting College policy, it was considered that it might be useful to the membership as a discussion document. Any member wishing to obtain a copy should write to: The Secretary, The Royal College of Psychiatrists, 17 Belgrave Square, London SW1X 8PG. Copies will cost $£ 1.50$ (postage and packing included) and cheques should be made payable to the Royal College of Psychatrists.

(For details about 'Confidentiality and Forensic Psychiatry'-see page 201). 